\title{
Chemistry and Biology of Radiotracers That Target Changes in Sympathetic and Parasympathetic Nervous Systems in Heart Disease
}

\author{
William C. Eckelman ${ }^{1}$ and Vasken Dilsizian ${ }^{2}$ \\ ${ }^{I}$ Molecular Tracer LLC, Bethesda, Maryland; and ${ }^{2}$ Department of Diagnostic Radiology and Nuclear Medicine, University of \\ Maryland School of Medicine, Baltimore, Maryland
}

\begin{abstract}
Following the discovery of the sympathetic and parasympathetic nervous system, numerous adrenoceptor drugs were radiolabeled and potent radioligands were prepared in order to image the $\beta$ adrenergic and the muscarinic systems. But the greatest effort has been in preparing noradrenaline analogs, such as norepinephrine, ${ }^{11} \mathrm{C}$-metahydroxyephedrine, and ${ }^{123}$-metaiodobenzylguanidine that measure cardiac sympathetic nerve varicosities. Given the technical and clinical challenges in designing and validating targeted adrenoceptor-binding radiotracers, namely the heavily weighted flow dependence and relatively low target-to-background ratio, both requiring complicated mathematic analysis, and the inability of targeted adrenoceptor radioligands to have an impact on clinical care of heart disease, the emphasis has been on radioligands monitoring the norepinephrine pathway. The chemistry and biology of such radiotracers, and the clinical and prognostic impact of these innervation imaging studies in patients with heart disease, are examined.
\end{abstract}

Key Words: cardiac innervation; heart failure; norepinephrine; metaiodobenzylguanidine; hydroxyephedrine; fluoro-m-hydroxyphenethylguanidine

J Nucl Med 2015; 56:7S-10S

DOI: 10.2967/jnumed.114.142802

$\mathbf{T}$ he discovery of the sympathetic and parasympathetic fibers of the autonomic nervous system in the heart and their importance in patients with heart failure encouraged radiopharmaceutical scientists to develop pharmaceutical drug analogs. The focus to date has been on noradrenaline mimetics to identify the subsets of patients who are at high risk of adverse cardiac events, such as progression of heart failure, arrhythmic events, or sudden cardiac death.

\section{DISCOVERY OF THE SYMPATHETIC AND PARASYMPATHETIC NERVOUS SYSTEM}

Although Otto Loewi (1) discovered the chemical transmission of nerve impulses using acetylcholine, it was von Euler (2) who, in 1946, discovered that the true agent of sympathetic trans-

Received Nov. 10, 2014; revision accepted Jan. 5, 2015.

For correspondence or reprints contact: William C. Eckelman, Molecular Tracer LLC, 7710 Woodmont Ave., Apt. 1109, Bethesda, MD 20814.

E-mail: wceckelman@gmail.com

COPYRIGHT (c) 2015 by the Society of Nuclear Medicine and Molecular Imaging, Inc. mission is noradrenaline, also known as norepinephrine. That led to the differentiation of adrenergic and cholinergic neurons and synapses.

The parasympathetic nervous system uses chiefly acetylcholine as its neurotransmitter, although peptides, such as cholecystokinin, may act on the parasympathetic nervous system as a neurotransmitter. Acetylcholine acts on 2 types of receptors, the muscarinic and nicotinic cholinergic receptors. Most transmissions occur in 2 stages: when stimulated, the preganglionic nerve releases acetylcholine at the ganglion, which acts on nicotinic receptors of postganglionic neurons. The postganglionic nerve then releases acetylcholine to stimulate the muscarinic receptors of the target organ.

The (ortho-)sympathetic nervous system is 1 of 3 major parts of the autonomic nervous system, the others being the enteric and parasympathetic systems. The general action of the sympathetic nervous system is to mobilize the body's nervous system fight-orflight response. However, it is constantly active at a basic level to maintain homeostasis. Given the in vivo effects of noradrenaline, $\beta$-adrenoreceptor antagonists were an early choice for treating patients with hypertension, angina pectoris, and cardiac arrhythmias (3).

Numerous adrenoceptor drugs have been radiolabeled, either replacing carbon with radioactive ${ }^{11} \mathrm{C}$ or adding a radioactive nuclide such as ${ }^{123} \mathrm{I}$ or ${ }^{18} \mathrm{~F}$. Less effort has been put into radiolabeling $\alpha$-adrenoceptor drugs. For the $\alpha$ adrenoceptor, only ${ }^{11} \mathrm{C}-\mathrm{GB} 67$ (N2[6-[(4-amino-6,7-dimethoxy-2-quinazolinyl)(methyl)amino]hexyl]$\mathrm{N} 2-{ }^{11} \mathrm{C}$-methyl-2-furamide hydrochloride) has been developed. Its potential for application in patients has not been assessed (4).

For both the $\beta$-adrenergic and the muscarinic systems, potent PET radioligands have been prepared and evaluated in patients. For muscarinic receptor-binding radioligands for cardiac applications, $N-{ }^{11} \mathrm{C}$-methylquinuclidinyl benzilate $\left({ }^{11} \mathrm{C}-\mathrm{MQNB}\right)$ is the primary example, and for the $\beta$ adrenoreceptor, several radiotracers have been developed in efforts to quantitate the receptor density-for example, using ${ }^{11} \mathrm{C}-\mathrm{CGP} 12177$ ( $S$-(3'-t-butylamino2 '-hydroxypropoxy)-benzimidazol-2- ${ }^{11} \mathrm{C}$-one) and ${ }^{11} \mathrm{C}$-CGP12388 ((S)-4-(3-(2' - ${ }^{11} \mathrm{C}$-isopropylamino)-2-hydroxypropoxy)-2H-benzimidazol2-one) (5).

But the greatest effort has been in preparing noradrenaline analogs that measure aspects of the uptake system $(6,7)$. For example, the uptake of norepinephrine, ${ }^{11} \mathrm{C}$-metahydroxyephedrine $\left({ }^{11} \mathrm{C}-\mathrm{HED}\right)$, and ${ }^{123} \mathrm{I}$-metaiodobenzylguanidine ( $\left.{ }^{123} \mathrm{I}-\mathrm{MIBG}\right)$ into cardiac sympathetic nerve varicosities has been studied. After extraction from plasma, HED and MIBG are transported into sympathetic nerve terminal axons by the norepinephrine transporter (NET). Once in the neuronal axoplasm, they are subsequently transported into norepinephrine 


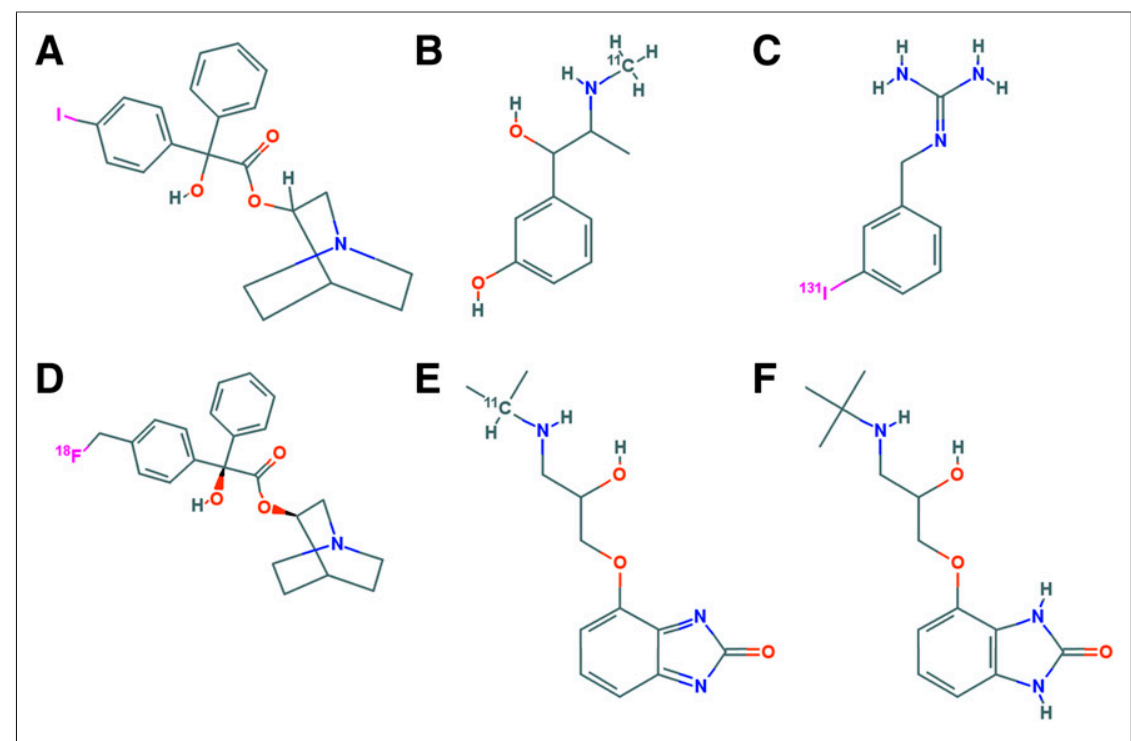

FIGURE 1. Structures of muscarinic and $\beta$-adrenoceptor antagonists and norepinephrine analogs. Shown are quinuclidinyl RS 4 - ${ }^{123}$-benzilate (A), ${ }^{11} \mathrm{C}$-metahydroxyephedrine (B), ${ }^{123 / 131}$ I-MIBG (C), quinuclidinyl 4-18 F-fluoromethylbenzilate (D), ${ }^{11} \mathrm{C}$ (one) CGP12177 (E), and ${ }^{11} \mathrm{C}-\mathrm{CGP} 12388$ (F). (Adapted from PubChem.)

storage vesicles by the second isoform of the vesicular monoamine transporter.

\section{CHEMISTRY}

Except for $\mathrm{N}$-methylation using ${ }^{11} \mathrm{C}$ methyl iodide or triflate, preparing the precursor for the radiofluorination or radioiodination is complicated. In one case introducing an ${ }^{11} \mathrm{C}$ into the $N$-methyl 3-quinuclidinyl benzilate, the ${ }^{11} \mathrm{C}$ was introduced by an $N$-methylation (Fig. 1). There is also a quinuclidinyl $4-{ }^{18} \mathrm{~F}$-fluoromethylbenzilate that was taken up in the myocardium but also showed uptake in the bone (8). For the $2 \beta$-adrenoceptor ligands, ${ }^{11} \mathrm{C}$-CGP12177 ( $S$-(3'-t-butylamino-2' -hydroxypropoxy)-benzimidazol-2- ${ }^{11} \mathrm{C}$-one) and ${ }^{11} \mathrm{C}-\mathrm{CGP} 12388\left((S)-4-\left(3-\left(2^{\prime}-{ }^{11} \mathrm{C}\right.\right.\right.$-isopropylamino)-2-hydroxypropoxy)-2H-benzimidazol-2-one), the former is a complicated synthesis starting with ${ }^{11} \mathrm{C}$-phosgene followed by a multistep synthesis, whereas the latter is a more straightforward radiolabeling of the isopropyl group via a reductive alkylation by ${ }^{11} \mathrm{C}$-acetone of the corresponding $(S)$-desisopropyl compound $(9,10)$. The complicated synthesis of ${ }^{11} \mathrm{C}$-CGP12177 prevented a detailed clinical study. ${ }^{123}$ I-MIBG was originally synthesized by an exchange method using the nonradioactive MIBG. Later, the trialkyl tin precursor was used to increase the specific activity. A procedure using a solid-phase resin containing the covalently bound stannylbenzyl-guanidine precursor has the potential to produce the highest specific activity (11). This is important given the side effects. The structures of these compounds are shown in Figure 1.

\section{BIOLOGY}

Because the radiotracers targeting receptors, enyzmes, and transporters of the sympathetic and parasympathetic nervous system are small molecules, the radionuclides used were ones to introduce the minimal perturbation to the parent drug candidate from ${ }^{11} \mathrm{C}$, which replaced a stable carbon and therefore did not alter the biochemistry, to ${ }^{18} \mathrm{~F}$ and ${ }^{123} \mathrm{I}$, which produced changes in the biochemistry. The ${ }^{11} \mathrm{C}$ radioligands had the biochemical properties of the parent compound, often a well-characterized drug candidate. The ${ }^{18} \mathrm{~F}$ and ${ }^{123} \mathrm{I}$ analogs showed similarities in the biochemistry compared with the parent drug candidate, but extensive validation studies are needed to elucidate the key biochemical parameters. This validation requires extensive effort using in vitro and in vivo models. For example, the biochemistry of ${ }^{18} \mathrm{~F}$-fludeoxyglucose and ${ }^{18} \mathrm{~F}$-fluorothymidine are similar to that of deoxyglucose and thymidine, but there are key differences, and the biochemistry of fluorothymidine is more unlike that of thymidine than FDG is unlike deoxyglucose and glucose (12). It appears that the initial biodistribution of $\beta$-adrenergic-binding radioligands is heavily weighted by flow. In addition, the target density $\left(\mathrm{B}_{\max }\right)$ is not high compared with that of the affinity constant. The metrics derived from mathematic analysis using the 2-injection system with the most easily synthesized $\beta$-adrenoceptor ligand (CGP 12388) yielded $\mathrm{B}_{\max }$ values of $9.74 \pm 1.80 \mathrm{nM}$ and $\mathrm{a}$ dissociation constant $\left(\mathrm{K}_{\mathrm{d}}\right)$ of $0.58 \pm 0.22 \mathrm{nM}$. This yields $\mathrm{B}_{\max } / \mathrm{K}_{\mathrm{d}}=$ 17 , which is a rule of thumb taken from in vitro studies to predict the maximum bound-to-free ratio to be expected in vivo. In vitro measurements are made in the absence of metabolites, involve very low nonspecific binding (because it can be subtracted), and are conducted under true equilibrium conditions in the absence of confounding factors of delivery and permeability. Therefore, bound-to-free ratios provide best-condition values, which have never been achieved in vivo. This ratio is used primarily to eliminate potential targeted radioligands, but a maximal ratio of 50 to 100 would warrant further investigation (8).

Another ramification of this ratio is that a high ratio will be beneficial as the field moves to imaging tissue that is smaller than twice the instrument resolution. A paradigm shift is required to move from a slightly lower-affinity constant to be sensitive to changes in the $\beta$ adrenoceptor as a function of disease and treatment to one that achieves a high target-to-nontarget ratio in order to detect abnormalities smaller than twice the instrument resolution (13). Another important paradigm shift is the evaluation of the clinical need. For a nuclear imaging procedure to be effective as an addition to the current standard of practice, it should be proposed for an unmet diagnostic need in a disease with a poor prognosis (14).

The NET substrates have been more completely validated for measuring the kinetics of various key biochemical steps. The goal is not a diagnostic test per se, but increasing our understanding of the underlying mechanisms of autonomic dysfunction and its contribution to the manifestation and progression of cardiac diseases.

The search continues for a radioligand the distribution of which is not primarily affected by flow, but rather by moderate levels of cardiac denervation. The most recent attempt has been to find a radiotracer that has a lower extraction than MIBG or HED but is also transported at a slower rate into neurons and retained. The new lead compound is $4-{ }^{18} \mathrm{~F}$-fluoro-m-hydroxyphenethylguanidine $\left({ }^{18} \mathrm{~F}\right.$ 4-F-MHPG) (15). The compound was originally compared with norepinephrine and HED using the Michaelis-Menten enzyme 
TABLE 1

Binding Affinities and Michaelis-Menten Transport Parameters (6)

\begin{tabular}{lcccc}
\hline \multicolumn{1}{c}{ Name } & $\mathrm{K}_{\mathrm{l}}(\mu \mathrm{M})$ & $\mathrm{K}_{\mathrm{m}}(\mu \mathrm{M})$ & $\mathrm{V}_{\max }$ & $\mathrm{V}_{\text {max }} / \mathrm{K}_{\mathrm{m}}$ \\
\hline Norepinephrine & $63.9 \pm 2.3$ & $0.28 \pm 0.03$ & $5.83 \pm 0.49$ & $21.3 \pm 2.4$ \\
HED & $43.2 \pm 1.8$ & $0.48 \pm 0.08$ & $5.43 \pm 0.71$ & $11.4 \pm 1.3$ \\
4-18F-MHPG & $5.6 \pm 0.5$ & $2.57 \pm 0.35$ & $7.46 \pm 0.64$ & $3.0 \pm 0.5$ \\
HED & - & - & - & $2.66 \pm 0.39$ \\
MIBG & 0.052 & 0.23 & 4.4 & $3.6 \pm 0.2$ \\
\hline
\end{tabular}

$\mathrm{K}_{\mathrm{l}}=$ binding affinity; $\mathrm{K}_{\mathrm{m}}=$ Michaelis constant; $\mathrm{V}_{\max }=$ maximum velocity.

Data are for cloned human norepinephrine transporter stably expressed in rat C6-glial cells. Using tritium-labeled compounds, 7 different unlabeled substrate concentrations were added; 3 compounds are reported here. Cellular uptake was analyzed by MichaelisMenten equations. C6-human NET membrane was used for binding assays. For competitive binding assays, percentage of specific binding vs. inhibitor concentration data was fitted to one-site competition model. $K_{1}$ values were calculated from estimated inhibition concentration of $50 \%\left(\mathrm{IC}_{50}\right)$ using Cheng-Prusoff correction, $\mathrm{K}_{\mathrm{I}}=\mathrm{IC}_{50} /\left(1+\mathrm{L}^{*} / \mathrm{KD}\right)$, where $\mathrm{L}^{*}$ is ${ }^{3} \mathrm{H}$-mazindol concentration used, and $\mathrm{KD}$ was set to mean value from control saturation assays $(1.20 \mathrm{nM})$. Units are $\mu \mathrm{L} / \mathrm{min} / \mathrm{mg}$ of protein for these in vitro studies. Final 2 rows are neuronal uptake rates that are measures of $\mathrm{V}_{\max } / \mathrm{K}_{\mathrm{m}}$ from isolated rat heart studies and not C6-hNET in vitro studies. Units are $\mathrm{mL} / \mathrm{min} / \mathrm{g}$ of wet weight for these studies.

analysis (Table 1). The analysis in the current study was performed using a compartment model (net uptake, inhibition constant $=$ $0.341 \mathrm{~mL} / \mathrm{min} / \mathrm{g}$ ) and the Patlak analysis (Patlak slope $=0.302$ $\mathrm{mL} / \mathrm{min} / \mathrm{g}$ ). Note that ${ }^{4}{ }^{18} \mathrm{~F}-\mathrm{FMHPG}$ has a weaker Michaelis constant with about the same maximum velocity, which was the design goal to minimize competition by norepinephrine (6).

\section{SELECTION OF PROPER IMAGING TARGETS BASED ON NEUROHORMONAL CHANGES IN HEART FAILURE}

Given the technical and clinical challenges in designing and validating targeted adrenoceptor-binding radiotracers-namely, the heavily weighted flow dependence and relatively low targetto-background ratio, both requiring complicated mathematic analysis, and the inability of targeted adrenoceptor radioligands to have an impact on clinical care of heart disease - the emphasis has been on radioligands monitoring the norepinephrine pathway.

One of the characteristic neurohormonal changes during heart failure is the activation of the sympathetic nervous system. In the acute phase of heart failure, there is increased release of norepinephrine from the presynaptic vesicles as a compensatory response to left ventricular dysfunction. The initial increase in sympathetic activity could promptly preserve cardiovascular homeostasis and even restore cardiac contractility. After the initial increase in sympathetic activity, with increased quantities of norepinephrine in the synaptic cleft, there is corresponding downregulation of the human NET, isoform 1 , transporter (decreased uptake-1 system) (16). Gradually, the compensatory mechanism is overwhelmed, and persistent excess of norepinephrine in the cleft eventually results in desensitization of the postsynaptic adrenergic receptors (17), myocyte apoptosis, and myocellular loss (18), worsening heart failure and increasing the susceptibility for arrhythmias and sudden cardiac death (19). Thus, persistent activation of the sympathetic nervous system can be deleterious (20) and ultimately lead to progressive worsening of left ventricular contractile function and heart failure.

In chronic heart failure, cardiac adrenoceptor signaling and function can appear significantly deranged and the adrenergic reserve of the heart diminished $(17,21,22)$. A small proportion of the norepinephrine spills into the bloodstream, increasing plasma norepinephrine levels. These compensatory changes can be a potential imaging target with norepinephrine analogs ${ }^{123}$ I-MIBG or ${ }^{11} \mathrm{C}$-HED and appear as decreased retention of the radiotracer in the presynaptic area and increased washout on planar, SPECT, or PET images $(16,23,24)$.

\section{THE CLINICAL AND PROGNOSTIC IMPACT OF THESE INNERVATION IMAGING STUDIES}

In the clinical setting, imaging heart failure patients using ${ }^{123} \mathrm{I}-$ MIBG or ${ }^{11} \mathrm{C}-\mathrm{HED}$ has repeatedly shown its usefulness in identifying patients who are at an increased risk of adverse cardiac events (25-27). MIBG and HED imaging may also identify patients with ischemic cardiomyopathy who are at high risk of sudden cardiac death $(24,28,29)$. With the exception of ${ }^{123}$ IMIBG, the clinical impact of these imaging studies has not led to Food and Drug Administration approval. ${ }^{123} \mathrm{I}-\mathrm{MIBG}$ and its radiotherapeutic analog, ${ }^{131} \mathrm{I}-\mathrm{MIBG}$, have been important in the diagnosis and treatment of neuroendocrine disease. ${ }^{123} \mathrm{I}-\mathrm{MIBG}$ has been assigned the generic name ${ }^{123}$ I-iobenguane sulfate and the commercial name AdreView (GE Healthcare). It is presently the first imaging agent approved for visualization of myocardial sympathetic innervation in certain heart failure patients $(27,30)$.

\section{CONCLUSION}

The change in receptor density as a function of disease severity and treatment is the major proposed indication for the development of radiotracers that target cardiac innervation. The attempts at quantitation of either the adrenoceptor or the muscarinic acetylcholine receptor in the myocardium are complicated techniques that are implemented because the initial biodistribution in the heart is heavily weighted by flow. To determine the change in receptor density as a function of treatment or disease, a procedure was developed based on a 2-data-point experiment measuring the blocking of the myocardial uptake of a no-carrier-added radioligand dose and extracting the receptor density from those data. This is a long and complicated patient procedure with the potential of low sensitivity. Studies to determine the extent of the occupancy of the targeted receptor by the drug appear to be less important in 
cardiology than in neurology given the ready access to techniques to measure surrogate metrics of target saturation.

The NET substrates have been more completely validated for measuring the kinetics of various key biochemical steps. The goal is not a diagnostic test per se, but to increase our understanding of the underlying mechanisms of autonomic dysfunction and its contribution to the manifestation and progression of cardiac diseases (30). The search continues for a radioligand having a distribution that is not primarily affected by flow but rather by moderate levels of cardiac denervation.

\section{DISCLOSURE}

No potential conflict of interest relevant to this article was reported.

\section{REFERENCES}

1. Zimmer H-G. Otto Loewi and the chemical transmission of vagus stimulation in the heart. Clin Cardiol. 2006;29:135-136.

2. Von Euler US. Some aspects of the clinical physiology of noradrenaline. Scand J Clin Lab Invest. 1952;4:254-262.

3. Moran NC. The development of beta adrenergic blocking drugs: a retrospective and prospective evaluation. Ann N Y Acad Sci. 1967;139:649-660.

4. Riemann B, Schäfers M, Law MP, Wichter T, Schober O. Radioligands for imaging myocardial alpha- and beta-adrenoceptors. Nuklearmedizin. 2003;42:4-9.

5. Elsinga PH, van Waarde A, Vaalburg W. Receptor imaging in the thorax with PET. Eur J Pharmacol. 2004;499:1-13.

6. Raffel DM, Chen W, Jung YW, Jang KS, Gu G, Cozzi NV. Radiotracers for cardiac sympathetic innervation: transport kinetics and binding affinities for the human norepinephrine transporter. Nucl Med Biol. 2013;40:331-337.

7. Raffel DM. Targeting norepinephrine transporters in cardiac sympathetic nerve terminals. In: Welch MJ, Eckelman WC. Targeted Molecular Imaging. Boca Raton, FL: CRC Press, Taylor \& Francis Group; 2012:305-318.

8. Eckelman WC. Design criteria for targeted molecules: muscarinic cholinergic systems biology. In: Welch MJ, Eckelman WC. Targeted Molecular Imaging. Boca Raton, FL: CRC Press, Taylor \& Francis Group; 2012:201-215.

9. Brady F, Luthra SK, Tochon-Danguy HJ, et al. Asymmetric synthesis of a precursor for the automated radiosynthesis of S-(3'-t-butylamino-2'-hydroxypropoxy)-benzimidazol-2- ${ }^{11} \mathrm{C}$-one $\left(\mathrm{S}-{ }^{11} \mathrm{C}-\mathrm{CGP} 12177\right)$ as a preferred radioligand for beta-adrenergic receptors. Int J Rad Appl Instrum A. 1991;42:621-628.

10. Elsinga PH, van Waarde A, Jaeggi KA, Schreiber G, Heldoorn M, Vaalburg W. Synthesis and evaluation of (S)-4-(3-(2'-11 C-isopropylamino)-2-hydroxypropoxy)2H-benzimidazol-2-one ((S)- $\left.{ }^{11} \mathrm{C}-\mathrm{CGP} 12388\right)$ and (S)-4-(3-((1'-18 F-fluoroisopropyl)amino)-2-hydroxypropoxy)-2H-benzimidazol-2-one ((S)-18 F-fluoro-CGP 12388) for visualization of beta-adrenoceptors with positron emission tomography. J Med Chem. 1997:40:3829-3835.

11. Barrett JA, Joyal JL, Hillier SM, et al. Comparison of high-specific-activity Ultratrace ${ }^{123 / 131}$ I-MIBG and carrier-added ${ }^{123 / 131}$ I-MIBG on efficacy, pharmacokinetics, and tissue distribution. Cancer Biother Radiopharm. 2010;25:299-308.

12. Krohn KA, Mankoff DA, Muzi M, Link JM, Spence AM. True tracers: comparing FDG with glucose and FLT with thymidine. Nucl Med Biol. 2005;32:663-671.
13. Eckelman WC, Jones AG, Duatti A, Reba RC. Progress using Tc-99m radiopharmaceuticals for measuring high capacity sites and low density sites. Drug Discov Today. 2013;18:984-991.

14. Eckelman WC, Lau CY, Neumann RD. Perspective, the one most responsive to change. Nucl Med Biol. 2014;41:297-298.

15. Jang KS, Jung YW, Gu G, et al. 4- ${ }^{18}$ F-fluoro-m-hydroxyphenethylguanidine: a radiopharmaceutical for quantifying regional cardiac sympathetic nerve density with positron emission tomography. J Med Chem. 2013;56:7312-7323.

16. Haider N, Baliga RR, Chandrashekhar Y, Narula J. Adrenergic excess, hNET1 down-regulation, and compromised mIBG uptake in heart failure: poverty in the presence of plenty. JACC Cardiovasc Imaging. 2010;3:71-75.

17. Bristow MR, Ginsburg R, Umans V, et al. Beta 1- and beta 2-adrenergic-receptor subpopulations in nonfailing and failing human ventricular myocardium: coupling of both receptor subtypes to muscle contraction and selective beta 1-receptor down-regulation in heart failure. Circ Res. 1986;59:297-309.

18. Narula J, Haider N, Virmani R, et al. Apoptosis in myocytes in end-stage heart failure. N Engl J Med. 1996;335:1182-1189.

19. Ellison KE, Stevenson WG, Sweeney MO, Epstein LM, Maisel WH. Management of arrhythmias in heart failure. Congest Heart Fail. 2003;9:91-99.

20. Rona G. Catecholamine cardiotoxicity. J Mol Cell Cardiol. 1985;17:291-306.

21. Bristow MR, Ginsburg R, Minobe W, et al. Decreased catecholamine sensitivity and beta-adrenergic-receptor density in failing human hearts. $N$ Engl J Med. 1982;307:205-211.

22. Port JD, Bristow MR. Altered beta-adrenergic receptor gene regulation and signaling in chronic heart failure. J Mol Cell Cardiol. 2001;33:887-905.

23. Chen W, Cao Q, Dilsizian V. Variation of heart-to-mediastinal ratio in ${ }^{123}$ I-mIBG cardiac sympathetic imaging: its affecting factors and potential corrections. Curr Cardiol Rep. 2011;13:132-137.

24. Klein T, Dilsizian V, Cao Q, Chen W, Dickfeld TM. The potential role of iodine-123 metaiodobenzylguanidine imaging for identifying sustained ventricular tachycardia in patients with cardiomyopathy. Curr Cardiol Rep. 2013; 15:359.

25. Merlet P, Valette H, Dubois-Rane JL, et al. Prognostic value of cardiac metaiodobenzylguanidine imaging in patients with heart failure. J Nucl Med. 1992; 33:471-477.

26. Verberne HJ, Brewster LM, Somsen GA, van Eck-Smit BL. Prognostic value of myocardial ${ }^{123}$ I-metaiodobenzylguanidine (MIBG) parameters in patients with heart failure: a systematic review. Eur Heart J. 2008;29:1147-1159.

27. Jacobson AF, Senior R, Cerqueira MD, et al. Myocardial iodine-123 metaiodobenzylguanidine imaging and cardiac events in heart failure: results of the prospective ADMIRE-HF (AdreView Myocardial Imaging for Risk Evaluation in Heart Failure) study. J Am Coll Cardiol. 2010;55:2212-2221.

28. Tamaki S, Yamada T, Okuyama Y, et al. Cardiac iodine-123 metaiodobenzylguanidine imaging predicts sudden cardiac death independently of left ventricular ejection fraction in patients with chronic heart failure and left ventricular systolic dysfunction: results from a comparative study with signal-averaged electrocardiogram, heart rate variability, and QT dispersion. J Am Coll Cardiol. 2009;53:426-435.

29. Fallavollita JA, Heavey BM, Luisi AJ Jr, et al. Regional myocardial sympathetic denervation predicts the risk of sudden cardiac arrest in ischemic cardiomyopathy. J Am Coll Cardiol. 2014;63:141-149.

30. Dilsizian V, Chandrashekhar Y, Narula J. Introduction of new tests: low are the mountains, high the expectations. JACC Cardiovasc Imaging. 2010;3:117-119. 